\title{
Characteristic Entities in PhotoStress Method
}

\author{
Peter Frankovský ${ }^{1, *}$, František Trebuňa ${ }^{2}$, Ján Kostka ${ }^{2}$, František Šimčák $^{2}$, Oskar Ostertag ${ }^{2}$, Wladysław Papacz $^{3}$ \\ ${ }^{1}$ Department of Mechatronics, Faculty of Mechanical Engineering, Technical University of Košice, Košice, Slovakia \\ ${ }^{2}$ Department of Applied Mechanics and Mechatronics, Faculty of Mechanical Engineering, Technical University of Košice, Košice, \\ Slovakia \\ ${ }^{3}$ Instytut Budowy i Eksploatacji Maszyn, Uniwersytet Zielonogórski, Zielona Góra, Poland \\ *Corresponding author: peter.frankovsky@tuke.sk
}

Received September 15, 2014; Revised October 01, 2014; Accepted October 30, 2014

\begin{abstract}
The presented paper describes characteristic entities in PhotoStress method - isoclinic fringes, singular points, isostatic lines, and isochromatic fringes. These entities are used in PhotoStress method to visualise and quantify deformation and stress fields of various photoelastically coated structural elements.
\end{abstract}

Keywords: isoclinic fringes, singular points, isostatic lines, isochromatic fringes

Cite This Article: Peter Frankovský, František Trebuňa, Ján Kostka, František Šimčák, Oskar Ostertag, and Władysław Papacz, "Characteristic Entities in PhotoStress Method." American Journal of Mechanical Engineering, vol. 2, no. 7 (2014): 239-243. doi: 10.12691/ajme-2-7-13.

\section{Introduction}

Reflection photoelasticity or PhotoStress method is an experimental method of mechanics which allows quantitative as well as qualitative analysis of directions and magnitudes of principal strains or principal normal stresses on a variety of structural elements.

Being universal, this method can be used in a variety of engineering applications such as structural analysis of engines, analysis of architectural structure solutions, development of prosthetic implants, development of structural components of planes, machines etc.

A photoelastic coating is used for the evaluation of deformation. This coating is applied with a special twocomponent adhesive on the analysed surface of the object under examination. When the object, which is subjected to loads, is illuminated with light from the reflection polariscope, it is possible to view isoclinic or isochromatic fringes, based on the polariscope settings.

For the purposes of a quantitative evaluation it is necessary to be familiar with parameters of isoclinic and isochromatic fringes in points of measurements. This paper presents the procedure of obtaining individual photoelastic entities, as well as a description of these entities.

\section{Isoclinic Fringes}

Isoclinic fringes (Figure 1) are defined as geometrical points in which directions of principal normal stresses are parallel to intersected polarisation planes of the polariser and the analyser. They occur at plane-polarised white light. Isoclinic fringes of a particular angle parameter $\alpha$ are related to a chosen direction of intersected polarisation planes of the polariser and the analyser, which is given by angle $\alpha$ or $\alpha+\pi / 2$ [1,2].

The creation of isoclines with regards to angle parameter $\alpha$ is a periodical phenomenon with period $\pi / 2$. With synchronous rotation of the polariser and the analyser, isoclinic fringes continuously change from the isoclines of angle parameter $\alpha=0^{\circ}$ up to angle parameter $\alpha=90^{\circ}$ in line with rotation angle of the polariser and the analyser.
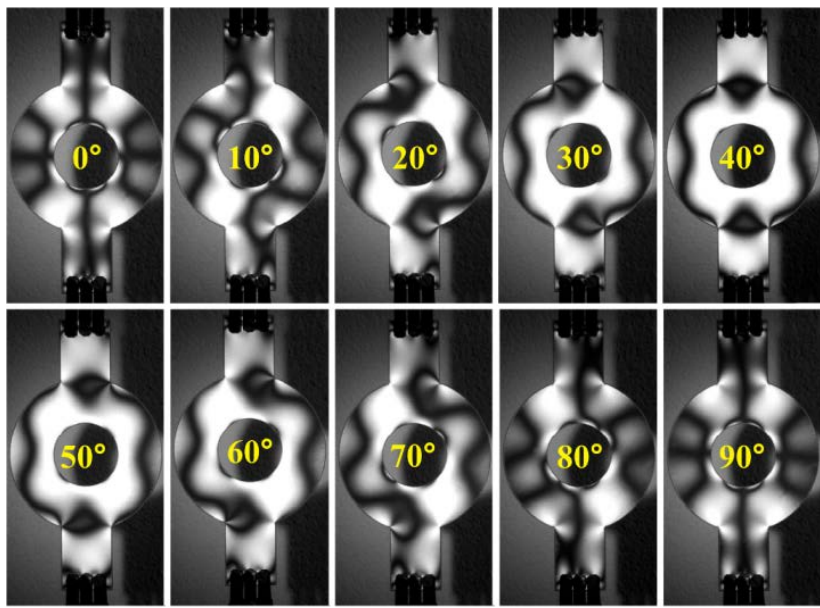

Figure 1. Isoclinic fringes

The creation of isoclines with regards to angle parameter $\alpha$ is a periodical phenomenon with period $\pi / 2$. With synchronous rotation of the polariser and the analyser, isoclinic fringes continuously change from the isoclines of angle parameter $\alpha=0^{\circ}$ up to angle parameter $\alpha=90^{\circ}$ in line with rotation angle of the polariser and the analyser. They are distributed along whole analysed surface of the object under examination simultaneously according to the changes in directions of principal normal stresses. The isoclinic fringe runs through every point of 
the surface under consideration with a specific angle parameter $\alpha$, as there is only one direction of principal stresses, i.e. direction $\alpha$, or $\alpha+\pi / 2$. However, there are points, fringes and surfaces which remain dark even during simultaneous rotation of the polariser and the analyser. Both principal normal stresses in such points, fringes and surfaces have identical magnitude in every direction. Through these points, fringes or surfaces are running isoclines of all angle parameters. These are called singular points, fringes or surfaces [3].

Angle parameter $\alpha$ changes from point to point along any curve $\mathrm{S}$ which runs through the point $\mathrm{P}$ (Figure 2).

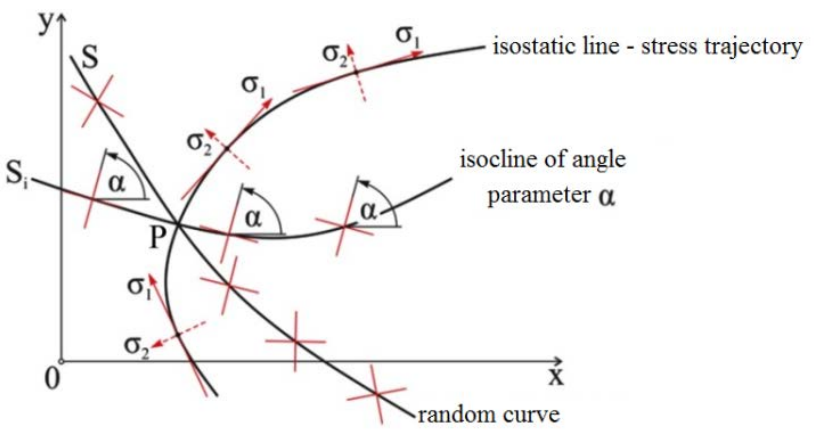

Figure 2. General example of an isocline and stress trajectory (isostatic line)

However, there is the $S_{i}$ curve which runs through the point $\mathrm{P}$. Along this curve the angle parameter $\alpha$ remains constant, while

$$
\frac{\partial \alpha}{\partial S_{i}}=0
$$

Provided that stress $\sigma_{\mathrm{x}}$ is known, $\sigma_{\mathrm{y}}$ and $\tau_{\mathrm{xy}}$, the equation of such isocline can be expressed mathematically as a relation

$$
\operatorname{tg} 2 \alpha=\frac{2 \operatorname{tg} \alpha}{1-\operatorname{tg}^{2} \alpha}=\frac{2 \tau_{\mathrm{xy}}}{\sigma_{\mathrm{x}}-\sigma_{\mathrm{y}}}=\text { konst. }
$$

where $\sigma_{\mathrm{x}}, \sigma_{\mathrm{y}}$ represent normal stresses, $\tau_{\mathrm{xy}}$ is shear stress and $\alpha$ represents isoclinic angle parameter. One specific isocline is related to every relevant constant.

Considering the equation (1), its can be concluded that

- the isocline with angle parameter $\alpha=0^{\circ}$ connects points in which shear stress $\tau_{x y}=0$ and normal stress $\sigma_{x} \neq \sigma_{y}$. On one side, the shear stress $\tau_{x y}>0$ and on the other side the shear stress $\tau_{x y}<0$.

- angle parameter $\alpha$ changes on the examined surface continuously and, as a result, other isoclines following each other do not intersect. Only one isocline can run through the analysed point, except for singular points $[1,5]$.

- the edge of the plane object subject to examination, which is not shear-loaded in tangential direction, has only principal normal stress $\sigma_{n}$ other than zero $\sigma_{n} \neq 0[1,5]$.

\section{Singular Points}

Points, in some cases lines and surfaces, which remain dark permanently even when rotating intersected polarisation filters, are called singular points, lines and surfaces. Shear stresses $\tau_{\mathrm{xy}}, \tau_{\mathrm{yx}}$ and the difference of principal normal stresses $\sigma_{1}-\sigma_{2}$ in singular points equal zero. In singular points the object is loaded with hydrostatic tension $\left(\sigma_{1}>0\right)$ or pressure $\left(\sigma_{1}<0\right)$, or is in a stressless state $\left(\sigma_{1}=0\right)$. Any direction in these points can be considered the direction of principal normal stresses. Isoclines of all angle parameters $\alpha$ intersect in singular points. As a result, isostatic lines in the area of singular point are largely curved what makes the drawing more difficult. The position of singular points can be identified on the basis of the picture of isochromatics, which appear as dark points, fringes or surfaces $[3,4]$.

According to rotation direction, singular points can be divided into two groups:

- positive singular points

- negative singular points.

When rotating the analyser clockwise (to the right) and isoclinic fringes are moving equally around the singular point, the singular point is positive (Figure 3).

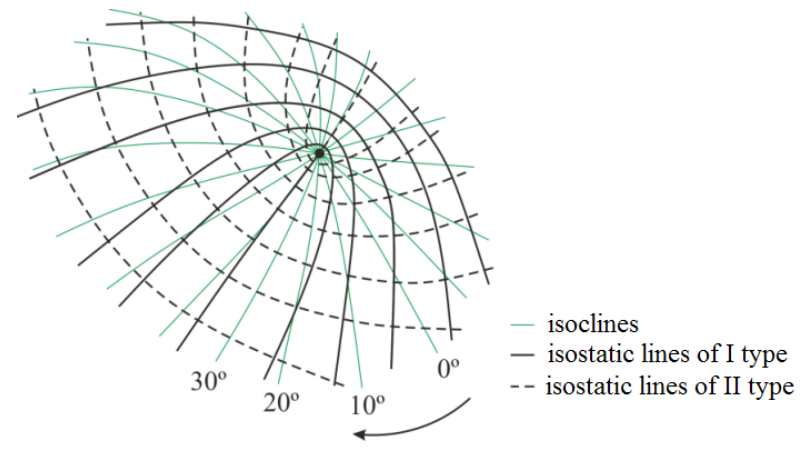

Figure 3. Positive singular point

Isoclinic fringes are moving in the opposite direction around negative singular point, i.e. anti-clockwise (Figure 4). Singular points which occur on the object's circumference are always negative.

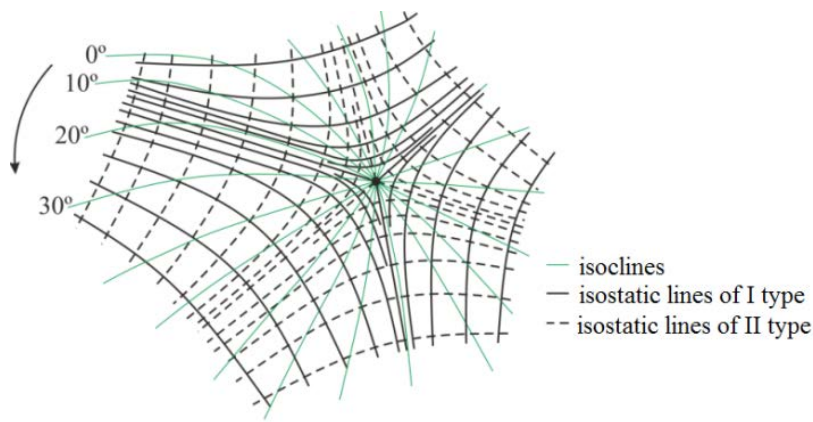

Figure 4. Negative singular point

Singular points can as well be classified as points of first order, points of second order and points of a higher order. Such classification respects the number of dark lines which run through given singular point. Singular points of second and a higher order are unstable with respect to the nature of mathematical expressions of stress components. It is manifested through decomposition to singular points of lower orders (e.g. point of second order breaks down to two points of first order) even after a small 
change in the shape of the object subject to examination. Figure 5 depicts singular points of different orders which occur in a network of isostatic curves $[3,4]$.

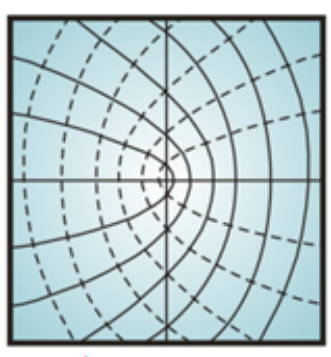

$1^{\text {st }}$ order

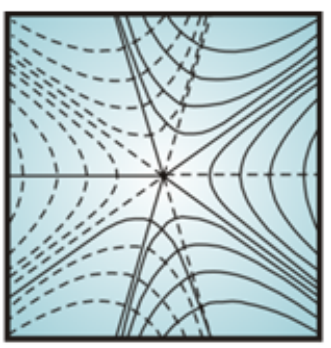

of $3^{\text {rd }}$ order

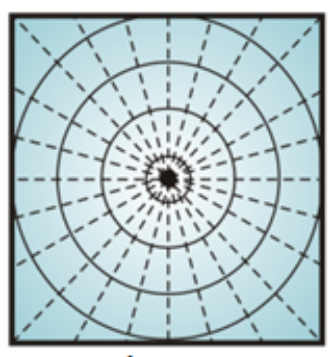

of $2^{\text {nd }}$ order

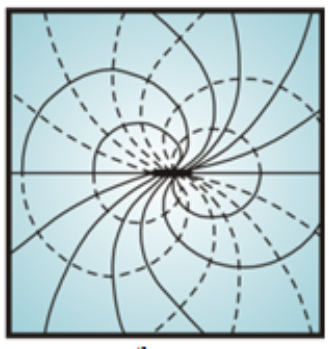

of $4^{\text {th }}$ order
Figure 5. Singular points

\section{Isostatic Lines}

Isostatic lines are lines which are characteristic for inner stress states. They provide informative overview of the behaviour of the object subject to examination. There are zero shear stresses along isostatic lines. Their tangents give the direction of principal normal stresses in every point of the analysed object [1].

Isoclinic lines do not offer direct representation of the direction of principal stresses. On the other hand, they provide us with data which are necessary to gain a set of isostatic lines (stress trajectories) of I and II type. Stress trajectories can be obtained via graphical construction, while the base for such construction of isostatic lines of I and II type is the set of isoclinic lines. Graphical construction of isostatic lines of I and II type is described in detail in given literature [4,5].

Isostatic lines can be expressed mathematically with equation

$$
\frac{\mathrm{dy}}{\mathrm{dx}}=\operatorname{tg} \alpha
$$

where angle $\alpha$ is defined by the expression which derives from the Mohr's circle (Figure 6) [3,4].

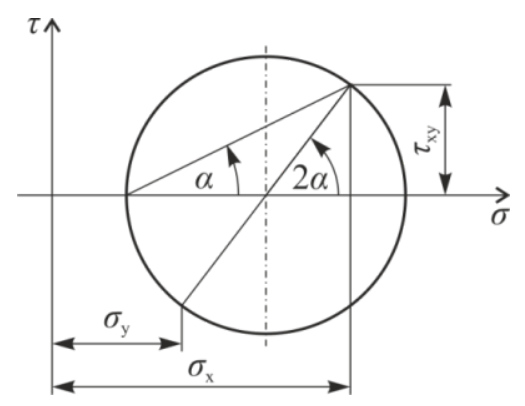

Figure 6. Mohr's circle of stresses

Considering the Mohr's circle (Figure 6):

$$
\operatorname{tg} 2 \alpha=\frac{2 \tau_{\mathrm{xy}}}{\sigma_{\mathrm{x}}-\sigma_{\mathrm{y}}}
$$

Adjusting the relation (2) and after substitution for

$$
\operatorname{tg} \alpha=\frac{-1+\sqrt{1+\operatorname{tg}^{2} 2 \alpha}}{\operatorname{tg} 2 \alpha}
$$

a differential equation of isostatic lines of I type emerges in the following form:

$$
\frac{\mathrm{dy}}{\mathrm{dx}}=\frac{-\left(\sigma_{\mathrm{x}}-\sigma_{\mathrm{y}}\right)+\sqrt{\left(\sigma_{\mathrm{x}}-\sigma_{\mathrm{y}}\right)^{2}+4 \tau_{\mathrm{xy}}^{2}}}{2 \tau_{\mathrm{xy}}}
$$

Considering isostatic lines of II type which in every point are perpendicular to isostatic lines of I type:

$$
\frac{\mathrm{d} \bar{y}}{\mathrm{~d} \bar{x}}=-\frac{1}{\frac{\mathrm{dy}}{\mathrm{dx}}}=\frac{-2 \tau_{\mathrm{xy}}}{-\left(\sigma_{\mathrm{x}}-\sigma_{\mathrm{y}}\right)+\sqrt{\left(\sigma_{\mathrm{x}}-\sigma_{\mathrm{y}}\right)^{2}+4 \tau_{\mathrm{xy}}^{2}}} .
$$

Given differential equations (6) and (7) define both types of isostatic lines.

Figure 7 shows the set of isostatic lines of I and II type in a half plane loaded by a single force [3].

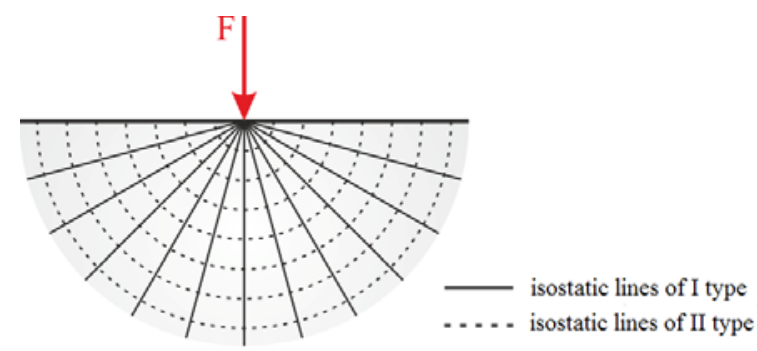

Figure 7. Set of isostatic lines in a half plane loaded by a single force

\section{Isochromatic Fringes}

Isochromatic fringes are known as connecting lines of points along which the difference of principal normal stresses $\sigma_{1}-\sigma_{2}$ is constant. They appear on an illuminated photoelastic coating as lines of single (iso) colour (chromos). They can be observed under circular polarised light [3,6]. Figure 8 shows isochromatic fringes during gradual diametrical tensional loading of the photoelastically coated sample [2].
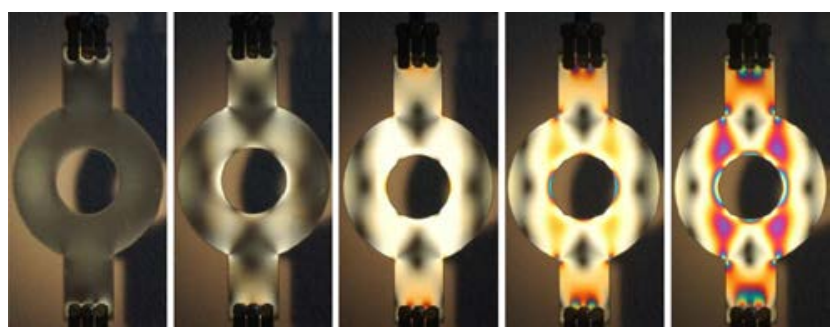

Figure 8. Isochromatic fringes

Linear dependency between temporary birefringence and the difference of principal strains or principal normal stresses enables us to determine the plane stress state on the surface of a photoelastically coated object. There is a constant phase shift of light waves along individual 
isochromatic fringes, i.e. isochromatics are geometrical locations of constant birefringence points $[7,8]$.

When white light is used, photoelastic pattern appears as a series of gradual isochromatic areas of different colours, while every area represents a different birefringence level related to that particular deformation in the object subject to examination. The colour of every area (isochromatic fringe) uniquely identifies the birefringence or the fringe order (deformation level) throughout the whole area. The characteristics of colourful isochromatic fringes are listed in Table 1 [1,5].

The orders of isochromatic fringes in the photoelastic coating are proportional to the difference between principal strains in the coating and on the surface of the object subject to examination. This linear relation can be expressed in terms of the following relation:

$$
\varepsilon_{1}-\varepsilon_{2}=f \cdot\left(N-N_{0}\right)=\gamma_{\max }
$$

where $\varepsilon_{1}, \varepsilon_{2}$ represent principal strains in the given photoelastic coating,

$f$ - fringe constant of optical sensitivity of the photoelastic coating,

$N_{0}$ - fringe order identified in the measurement point during zero loading of the object under analysis (initial compensator value),

$N$ - fringe order identified in the measurement point during loading of the object under analysis (final compensator value),

$\gamma_{\max }$ - maximum shear deformation.

Table 1. Characteristics of colourful isochromatic fringes

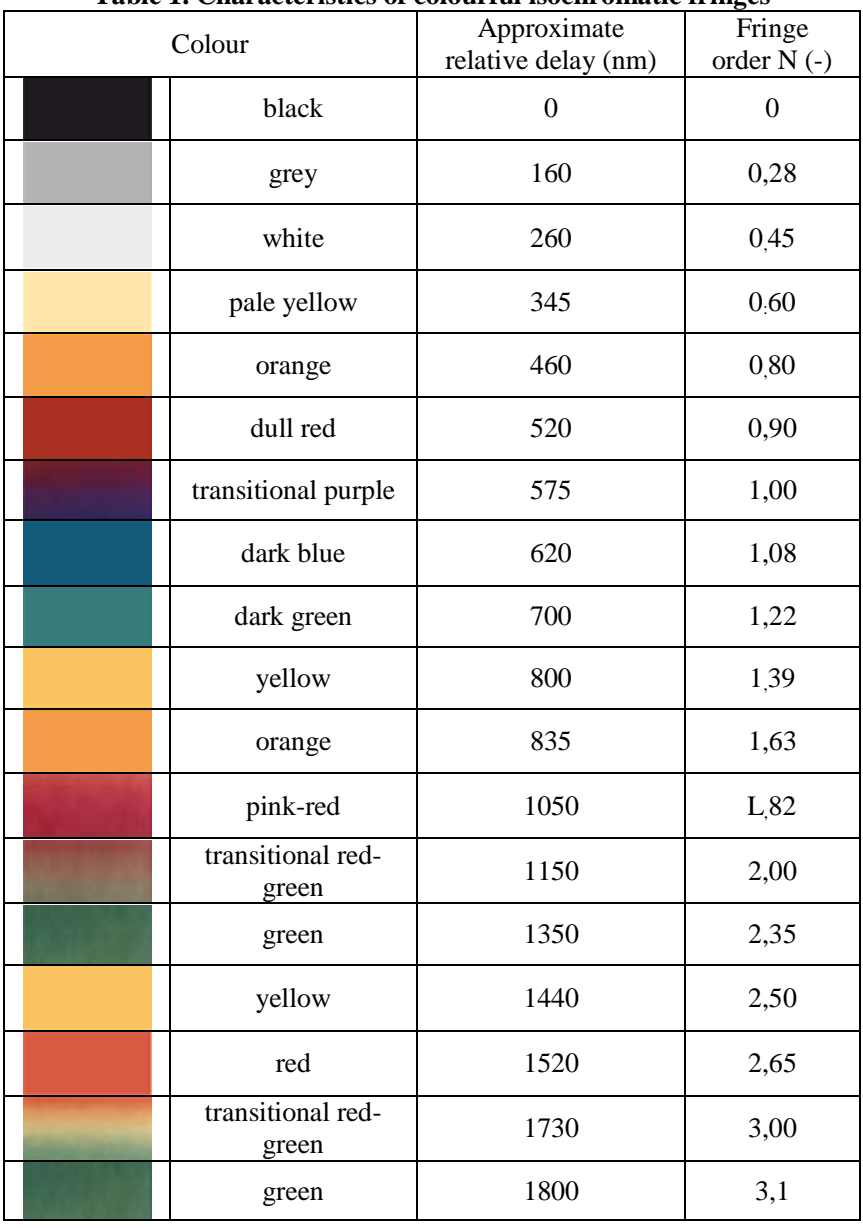

Engineering praxis more often uses stress than strain, hence equation (8) can be expressed via extended Hooke's law for biaxial stress state:

$$
\begin{gathered}
\sigma_{1}=\frac{E}{1-\mu^{2}}\left(\varepsilon_{1}+\mu \varepsilon_{2}\right) \\
\sigma_{2}=\frac{E}{1-\mu^{2}}\left(\varepsilon_{2}+\mu \varepsilon_{1}\right)
\end{gathered}
$$

Subtracting the relation (9) from the relation (10) gives expression for the difference of principal normal stresses in the following form:

$$
\sigma_{1}-\sigma_{2}=\frac{E}{1+\mu}\left(\varepsilon_{1}-\varepsilon_{2}\right)
$$

Implementing the relation (8) into the relation (11) gives the expression

$$
\sigma_{1}-\sigma_{2}=\frac{E}{1+\mu} f \cdot\left(N-N_{0}\right)
$$

Hooke's law for plane (biaxial) stress state can be used to apply experimentally gained photoelastic data to calculate the difference of principal normal stresses $\sigma_{1}-\sigma_{2}$ and maximum shear stress $\tau_{\max }$. Here applies the following

$$
\sigma_{1}-\sigma_{2}=\frac{E}{1+\mu}\left(\varepsilon_{1}-\varepsilon_{2}\right)=2 \tau_{\max }
$$

where $\sigma_{1}, \sigma_{2}$ principal normal stresses on the surface of the object under examination,

$E$ - modulus of elasticity of the material of which the analysed object is made,

$\mu$ - Poisson's ratio of the material of which the analysed object is made.

Maximum shear stress $\tau_{\max }$ on the photoelastic coating in any point can be expressed via relation

$$
\tau_{\max }=\frac{1}{2}\left(\frac{E}{1+\mu}\right) \cdot f \cdot\left(N-N_{0}\right)
$$

Relations (8) to (14) are principal relations which are used in the analysis of inner forces of the coated object under examination. They provide us only with the difference of principal strains or principal normal stresses and not with their individual magnitudes. In order to determine magnitudes of individual components and signs in case of a biaxial stress state, it is necessary to use numerical or experimental separation methods. In case of a plane (uniaxial) stress state ( $\sigma_{1}=0$ or $\sigma_{2}=0$ ) there is only one non-zero principal normal stress in the plane of the photoelastically coated object subjected to the analysis. This stress can be identified directly from the equation (12) [5]. For instance, the following relation applies for $\sigma_{2}=0$

$$
\sigma_{1}=\frac{E}{1+\mu} f \cdot\left(N-N_{0}\right)
$$

\section{Conclusion}


All photoelastic entities discussed above (isoclinic fringes, singular points, isostatic lines, isochromatic fringes) are necessary for the analysis of deformation and stress fields of various structural elements by means of PhotoStress method.

Parameters of isoclinic as well as isochromatic fringes are still determined manually in the majority of cases, even though we face advancing software support tools. However, PhotoStress software is has currently been developed at the workplace of the authors, which is based on classic methods in combination with digital records and modern hardware. The software will enable to quantify directions and magnitudes of principal strains and principal normal stresses on the basis of records of isoclinic and isochromatic fringes. Furthermore, it will be able to draw isostatic lines of I and II type automatically within particular field of the structural element under consideration.

\section{Acknowledgement}

This research was supported by grant project VEGA 1/0393/14, VEGA 1/0937/12 and KEGA 004TUKE$4 / 2013$.

\section{References}

[1] Trebuňa, F., Jadlovský, J., Frankovský, P., Pástor, M.: Automatizácia v metóde Photostress [Automation in PhotoStress method]. 1. issue. Košice: TU - 2012. 285 p.

[2] Huňady, R., Trebuňa, F., Frankovský, P., "Uplatnenie metódy PhotoStress[Application of PhotoStress method]," In: Strojárstvo. Vol. 15, No. 12, 2011, p. 10-12.

[3] Milbauer, M., Perla, M.: Fotoelasticimetrie a přiklady jejího použití [Photoelasticity and Examples of its Use]. CSAV, 1961.

[4] Milbauer, M., Perla, M.: Fotoelasticimetrické prristroje a měricí metody [Photoelasticity Devices and Measurement Methods]. ČSAV, 1959.

[5] Trebuňa, F.: Princípy, postupy, prístroje v metóde photostress [Principles, Processes, Devices in PhotoStress Method]. Typopress, Košice, 2006.

[6] Frocht, M. M.: Photoelasticity, John Wiley and Sons, New York, 1941.

[7] Kobayashi, A. S.: Handbook on experimental mechanics. New York: VCH, 1993.

[8] Zandman, F., Redner, S. T., Riegner, E. I.: "Reinforcing effect of birefringent coatings," Experimental Mechanics, (2), pp. 55-64, 1962. 